\title{
Assessment of the Implementation of Ventilator-associated Pneumonia Preventive Bundle in Pediatric Intensive Care Unit
}

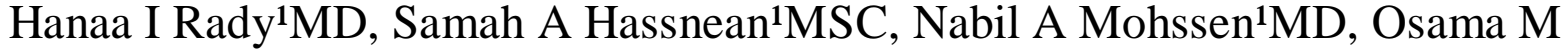 \\ Abdel AziziMD \\ The institutional affiliation of all authors: 'Department of pediatrics, Faculty of Medicine, Cairo University, \\ Cairo, Egypt
}

\begin{abstract}
Background: Pneumonia associated with mechanical ventilation (VAP) is one of the important causes of nosocomial infections in pediatric intensive care units (PICU). VAP is the leading cause of morbidity and mortality in PICUs. Aim: To assess the compliance to ventilator bundle components: elevation of the head of bed $>30$, sedation interruption, spontaneous breathing trial, peptic ulcer prophylaxis and its effect on the prevention of VAP. Subjects and Methods: A case control study at PICU of Abo EL Reish El Moneira Hospital, including all mechanically ventilated patients admitted over a period of one year. The study tested the effect of implementation of this bundle as regard the rate of VAP in both group, compliance to bundle and most affecting component of it. Results: There was decrease incidence of VAP after implementation of the bundle, from (50\%) to (14\%). Development of VAP was mostly affected by being in supine position, long duration of mechanical ventilation and presence of pump failure. $(p<0.05)$ The compliance to bundle components was statistically significant, $p=0.001$. Conclusion: VAP rate decreased after implementation of this bundle. Elevation of the head of bed was the most compliant component of bundle in the PICU.
\end{abstract}

Key words: Effective, Pediatric Intensive Care, Ventilator-associated pneumonia, Ventilator bundle

\section{Introduction}

Ventilator-associated pneumonia (VAP) is defined as pneumonia in mechanically ventilated patients that develops later than or at $48 \mathrm{hrs}$ after the patient has been placed on mechanical ventilator and have developed abnormal chest radiography with either one of the following symptoms: fever (38 or more) with no other recognized cause, leucopenia $\left(4,000 \mathrm{lmm}^{2}\right.$ or less), leucocytosis $\left(13,000 \mathrm{lmm}{ }^{2}\right.$ or more). In addition, patients should have at least two changes either in the sputum character, respiratory secretions, cough or worsening of gas exchange ( $\mathrm{O} 2$ desaturation, increased $\mathrm{O} 2$ requirements or increased ventilation demand). (1) VAP is the second common hospital-acquired infection among ICU patients occurring at variable rates from 6 to $52 \%$. (2) It is the leading cause of death in the intubated patients. Hospital mortality in ventilated patients who develop VAP is $46 \%$, compared to $32 \%$ for ventilated patients without VAP. (3)

The risk factors for developing VAP were found to be genetic syndromes, transport out of the PICU, reintubation, prior antibiotic use, continuous enteral feeding, immune-suppressants, immunodeficiency, neuromuscular blockade, some medications such as steroids and $\mathrm{H} 2$ blockers. The most commonly isolated organisms in VAP were staphylococcus aureus and pseudomonas aeurogenosa. (4)

Because of higher incidence and costs of VAP, there are several recommendations to decrease it. The health care infection control practices advisory committee suggests using oro-tracheal tubes instead of naso-tracheal tubes when the patients require mechanical ventilation, changing breathing circuits of ventilator only if malfunction or visibly contaminated and using endo-tracheal tubes with dorsal lumen to allow respiratory secretions to drain. (5) Lately, health care infection control practices advisory committee suggested also implementing ventilator bundle which resulted in dramatic reductions in the incidence of VAP.

The ventilator bundle has four key components

- Elevation of the head of the bed to between 30 and 45 degrees.

- Daily "sedation vacation" and daily assessment of readiness for extubation.

- Peptic ulcer disease prophylaxis (unless contraindicated).

- Deep venous thrombosis (DVT) prophylaxis (unless contraindicated). (6)

We aimed to study the prevalence and risk factors of VAP in ventilated patients admitted in PICU and to assess the impact of implementing head of bed elevation, sedation vacation and peptic ulcer prophylaxis on VAP rates.

\section{Patients \& Methods}

This study included all patients admitted to the medical PICU of Abol Reish El Monira Hospital, Cairo University, and are mechanically ventilated, from March 2010 till March 2011. 
We had two groups:

$1^{\text {st }}$ group: Patients admitted to PICU before implementation of the preventive bundle (from March 2010 to August 2010) and they are 22 patients: considered as control.

$2^{\text {nd }}$ group: Patients admitted to PICU after implementation of the preventive bundle (from September 2010 to March 2011). They are 43 patients: considered as cases.

All patients were subjected to full history and clinical examination. Routine laboratory investigations including complete blood count, C-reactive protein (CRP), eryhthrocyte sedimentation rate (ESR), arterial blood gases, liver and kidney functions, cultures and chest X-ray were done on admission and repeated as needed.

Patients were diagnosed as having VAP with:

Clinical evaluation: fever, new onset of purulent sputum, change in the character of the sputum, increased respiratory secretion or increased suction requirement, bronchial breath sounds and worsening gas exchange.

Laboratory investigation: Leucopenia or leukocytosis.

Chest radiography: Infiltrate, consolidation, cavitations and or pneumatoceles.

In this study we tested implementation of ventilator bundle suggested by Health Care Infection Control practices advisory committee in prevention of VAP in all ventilated patients upon their ventilation, by comparing VAP rate in the $1^{\text {st }}$ group with VAP rate in the $2^{\text {nd }}$ group after implementation of bundle components. The ventilator bundle has four key components (but we applied the first 3 only):

a) Elevation of the head of the bed to between 30 and 45 degrees.

b) Daily "sedation vacation" and daily assessment of readiness for extubation.

c) Peptic ulcer disease prophylaxis using sucralfate or ranitidine.

Since deep venous thrombosis is not recorded in our PICU except as complications of femoral vein sampling or cannulation, prophylaxis of DVT (the $4^{\text {th }}$ component) was not implemented.

Compliance to this bundle was assessed daily using a check list.

The exclusions from individual components of VAP bundle includes:

a) Sedation reviewed and, if appropriate, stopped each day.

Exclusions

- Paralyzed patient.

- Patient with brain injury, sedated with possible intra-cranial pressure problem.

- Patient who is difficult to oxygenate (Fio2> 0.7 or PEEP> 10)

- Patient who is difficult to ventilate - coughing, asynchrony.

- Patient receiving therapeutic hypothermia.

- Patient receiving palliative/terminal care.

b) Patient assessed for weaning and extubation each day.

Exclusions

- Paralyzed patient.

- Patient with brain injury, sedated with possible ICP problem.

- Patient who is difficult to ventilate - coughing, asynchrony.

- Patient who is difficult to oxygenate (Fio2 > 0.7 or PEEP > 10).

- Patient receiving therapeutic hypothermia.

- Patient receiving palliative/terminal care.

c) Avoid supine position and aim to have the head of bed elevated to at least $30^{\circ}$.

Exclusions

- Unstable, shocked patient e.g., requiring fluid challenges, high dose inotropes.

- Unstable pelvic or spinal injury (it may be possible to tilt the whole bed).

We also analyzed the association between VAP and certain risk factors as immunosuppressive diseases, immunosuppressive drugs, and invasive procedures as central venous line or urinary catheter.

\section{Statistical Analysis}

Data were statistically described in terms of range, mean \pm standard deviation $( \pm \mathrm{SD})$, median, frequencies (number of cases) and percentages when appropriate. Comparison of numerical variables between the two groups was done using Mann Whitney $U$ test for independent samples. For comparing categorical data, Chi square $\left(\chi^{2}\right)$ test was performed. Exact test was used instead when the expected frequency is less than 5. For comparing categorical data, Chi square $\left(\chi^{2}\right)$ test was performed. Yates correction equation was used instead when the expected frequency is less than 5. $P$ values less than 0.05 was considered statistically significant. All statistical calculations were done using computer programs SPSS (Statistical Package for the Social Science; SPSS Inc., Chicago, IL, USA) version 15 for Microsoft Windows. 


\section{Results}

A case-control study for prevention of VAP was performed in the PICU of Abo El Reesh El Monira Hospital. Sixty five patients (admitted and put on mechanical ventilation during the study period) were included. The controls were 22 patients and were not subjected to ventilator bundle approach and 43 patients were subjected to ventilator bundle approach (cases). The implementation of the bundle and the assessment of compliance were applied daily from day one to the end of the ventilation days.

Patient's demographics, underlying diseases, procedures, outcome and the reason for ventilation are summarized in Table1. The main reason for ventilation was lung failure $(66.15 \%)$. Overall mortality was (46.15\%), VAP mortality rate patients was higher $(83.3 \%)$ than non-VAP patients $(35.1 \%)$. The overall mean ventilation duration was 10.89 days. The overall mean length of stay was 12.77 days.

Table (1): Pediatric intensive care unit patient $s$ characteristics

\begin{tabular}{|l|l|l|l|}
\hline & $\mathbf{N}$ & $\mathbf{\%}$ & Mean \\
\hline Demographics & & & \\
\hline Male & 33 & 50.77 & \\
\hline Female & 32 & 49.23 & \\
\hline Age (Month) & & & 22.4 \\
\hline Underlying illness & & & \\
\hline Pulmonary disease & 39 & 60 & \\
\hline CNS disease & 17 & 26.15 & \\
\hline Other diseases * & 7 & 10.77 & \\
\hline Neuromuscular disease & 2 & 3 & \\
\hline Possible risk Factors & & & \\
\hline Re-intubation & 58 & 90.0 & \\
\hline Prior use of Antibiotics & 65 & 100 & \\
\hline Central line insertion & 17 & 26.15 & \\
\hline Urinary catheter insertion & 4 & 6.15 & \\
\hline Immunodeficiency disease & 6 & 7.69 & \\
\hline Immunosuppressive drugs & 3 & 4.61 & \\
\hline Organ failure & 17 & 26.15 & \\
\hline Outcome & & & \\
\hline PICU- LOS(days) & & & 12.77 \\
\hline Overall Mortality rate & 30 & 46.1 & \\
\hline VAP & 14 & 83.3 & \\
\hline Non VAP & 16 & 35 & \\
\hline Duration of Ventilation(days) & & & 10.89 \\
\hline Pump failure & 43 & 66.15 & \\
\hline Lung failure & 22 & 33.84 & \\
\hline nervous system; PICU: pediatic ins & & \\
\hline
\end{tabular}

CNS: central nervous system; PICU: pediatric intensive care unit; LOS: length of stay; VAP: ventilator associated pneumonia.

*Other diseases: cardiovascular, gastrointestinal, metabolic, hematologic disorders

Six patients of the case-group developed VAP (17\%), while 11 patients of control group developed VAP (50\%), $\mathrm{p}=0.002$ as shown in Table $\mathbf{2}$.

Table (2): Comparison between cases and control in relation to ventilator associated pneumonia

\begin{tabular}{|l|l|l|}
\hline & Cases & Controls \\
\hline VAP + ve & & \\
\hline Number & 6 & 11 \\
\hline$\%$ & 14 & 50.0 \\
\hline VAP - ve & & \\
\hline Number & 37 & 11 \\
\hline$\%$ & 86.0 & 50.0 \\
\hline p value & 0.002 & \\
\hline
\end{tabular}

VAP: ventilator associated pneumonia

Univariate analysis comparing mechanically ventilated with and without VAP are summarized in Table 3. VAP was associated with the following procedures: re-intubation and central line insertion. There was positive correlation between re-intubation and VAP, but statistically insignificant $(\mathrm{P}=0.327)$. The association between 
$\mathrm{VAP}$ and central line and urinary catheter insertion was also statistically insignificant, $\mathrm{P}=0.754$ and $\mathrm{p}=0.566$; respectively. Relative risk (RR) of those with central line and those without in relation to VAP was 1.176.

Table (3): Analysis of possible risk factors predisposing to ventilator associated pneumonia

\begin{tabular}{|l|l|l|l|l|l|l|}
\hline \multirow{2}{*}{ Risk factors } & \multicolumn{2}{|c|}{ VAP + ve } & \multicolumn{2}{|l|}{ VAP - ve } & P value & \multirow{2}{*}{ RR } \\
\cline { 2 - 6 } & $\mathbf{n}$ & $\mathbf{\%}$ & $\mathbf{n}$ & $\mathbf{\%}$ & & \\
\hline Supine position & 17 & 100 & 11 & 22.9 & 0.001 & \\
\hline $\begin{array}{l}\text { Duration of ventilation } \\
\text { (days) }\end{array}$ & \multicolumn{2}{|l|}{ Mean 19.35} & \multicolumn{2}{|l|}{ Mean 7.9} & 0.0001 & \\
\hline Central line & 5 & 29.4 & 12 & 25.0 & 0.754 & 1.176 \\
\hline Re-intubation & 17 & 100 & 42 & 87.5 & 0.327 & \\
\hline Urinary catheter & 0 & 0.0 & 4 & 8.3 & 0.566 & \\
\hline Pump failure & 8 & 47.1 & 14 & 29.2 & 0.038 & 1.737 \\
\hline Lung failure & 9 & 52.9 & 34 & 70.8 & 0.236 & 0.576 \\
\hline Immunosuppressive Diseases & 0 & 0.0 & 6 & 12.5 & 0.327 & \\
\hline Immunosuppressive Drugs & 1 & 5.9 & 2 & 4.2 & 1.000 & 1.292 \\
\hline Organ failure & 2 & 11.8 & 15 & 31.3 & 0.198 & 0.376 \\
\hline Sepsis & 9 & 52.9 & 16 & 33.33 & 0.683 & \\
\hline Neurological diseases & 8 & 47.1 & 10 & 20.8 & 0.058 & \\
\hline
\end{tabular}

VAP: ventilator associated pneumonia

There was a statistically significant relation between the development of VAP and duration of mechanical ventilation, $\mathrm{p}=0.0001$; supine position, $\mathrm{p}=0.001$; and pump failure, $\mathrm{p}=0.038$.

The VAP +ve patients stayed in the PICU longer than VAP -ve patients, $\mathrm{p}=0.001$. Table 4

Table (4): Comparison between ventilator associated pneumonia +ve and -ve patients regarding length of stay

\begin{tabular}{|l|l|l|l|}
\hline & VAP - ve & VAP + ve & \multirow{2}{*}{ p value } \\
\cline { 1 - 2 } Length of stay (days) & & \multirow{2}{*}{0.001} \\
\cline { 1 - 3 } Mean \pm SD & $9.8-6.792$ & $21.00-10.92$ & \\
\cline { 1 - 3 } Median-Range & $7.00-(2-36)$ & $18.00-(6-37)$ & \\
\hline
\end{tabular}

VAP: ventilator associated pneumonia

The compliance to bundle components was statistically significant, $\mathrm{p}=0.001$ except for DVT prophylaxis which was not done in our study because our PICU was a medical ICU and the risk of developing DVT is very rare in our patients. Table 5

Table 5: The effect of ventilator bundle compliance on the outcome of cases

\begin{tabular}{|c|c|c|c|c|c|}
\hline & \multicolumn{2}{|l|}{ Dead cases } & \multicolumn{2}{|c|}{ Discharged cases } & \multirow{2}{*}{$\begin{array}{l}\mathbf{P} \\
\text { value }\end{array}$} \\
\hline & Mean \%-SD & $\begin{array}{l}\text { Median\%- } \\
\text { Range }\end{array}$ & Mean \%-SD & $\begin{array}{l}\text { Median\%- } \\
\text { Range }\end{array}$ & \\
\hline $\begin{array}{l}\text { Elevation of bed > } 45 \\
\text { compliance }\end{array}$ & $83.88 \%-19.44$ & $\begin{array}{l}96.87 \%-(54.1- \\
100)\end{array}$ & $98.37 \%-8.72$ & $\begin{array}{l}100.0 \%-(60.0- \\
111)\end{array}$ & 0.001 \\
\hline $\begin{array}{l}\text { Sedation interruption } \\
\text { compliance }\end{array}$ & $75.03-21.85$ & $\begin{array}{l}75.71-(43.2- \\
100)\end{array}$ & $96.03-10.45$ & $\begin{array}{l}100.0-(50.0- \\
106)\end{array}$ & 0.001 \\
\hline $\begin{array}{l}\text { Spontaneous } \\
\text { breathing compliance }\end{array}$ & $56.01-27.63$ & $\begin{array}{l}\text { 60.00-(0.0- } \\
100.0)\end{array}$ & 93.76-11.98 & $\begin{array}{l}100.0-(45.0- \\
100)\end{array}$ & 0.001 \\
\hline $\begin{array}{ll}\text { Peptic } & \text { ulcer } \\
\text { prophylaxis } & \\
\text { compliance } & \end{array}$ & \begin{tabular}{|l|}
$78.58-22.69$ \\
\end{tabular} & $\begin{array}{l}82.85-(43.2- \\
100)\end{array}$ & $94.96-12.02$ & $\begin{array}{l}100.0-(45.0- \\
100)\end{array}$ & 0.001 \\
\hline $\begin{array}{l}\text { All } \\
\text { compliance }\end{array}$ & $56.01-27.63$ & $\begin{array}{l}60.00-(0.0- \\
100.0)\end{array}$ & $93.76-11.98$ & $\begin{array}{l}100.0-(45.0- \\
100)\end{array}$ & 0.001 \\
\hline
\end{tabular}

\section{Discussion}

Before implementation of ventilator bundle, VAP rate was 50\%; and after implementation of ventilator bundle VAP rate decreased to $14 \%$. While searching other studies we found that the VAP rate varies widely: in their PICU, Yildizdas and colleagues 2002 (7) (44\%); Nolan and Berwick $2006 \underline{(8)}$ (22.72\%); Almuneef and colleagues $2004(9)(10.3 \%)$ and in their NICU, Yuan and colleagues $2007 \underline{(10)}(20.1 \%)$. This variation in the 
rates of VAP could be resulted from the type of patients admitted to each unit and the compliance to the bundle. Moreover, this variation indicates the difficulty that intensivists meet in the prevention of VAP due to its multifactorial predisposing factors.

Supine position, which reflects aspiration, appears to be important in the pathogenesis of VAP as demonstrate in our study and other studies. (11), (12) In this study, it was the $2^{\text {nd }}$ most significant risk factor predisposing to VAP after considering the prolonged duration of mechanical ventilation. Similarly, Ibrahim and colleagues 2001 (3) found a positive correlation between VAP and the duration of mechanical ventilation.

The presence of pump failure was found to be a significant risk factor in our study and in the study by Hina and colleagues 2010. (13)

In our study, there was significant relation between the compliance to each component of the VAP bundle and prevention of VAP, the most higher compliance was to elevation of the head of bed more than 45 degree $(97.8 \%$ of the ventilation days, $\mathrm{p}=0.000)$. Dorothy and colleagues $2010 \underline{(14)}$ proved that Head-of-bed elevation was the single element associated with reducing VAP in their patients. This is considered the simplest component of the bundle in its application, which gives intensivists hope that with some compliance, the VAP problem can be reduced.

\section{Conclusion}

The risk factors of developing VAP were prolonged duration of ventilation, supine position and neuromuscular diseases.

Bundle implementation was found effective in decreasing the VAP rate among our PICU patients. Elevation of the head of bed was the most compliant component of bundle in the PICU.

\section{LIMITATIONS}

We consider our small sample size, only 65 patients were studied, may limit its generalizability.

\section{RECOMMENDATION}

- Further evaluation of the bundle approach is needed in a wider sample scale.

- Additional studies estimating risk factors and outcome of VAP are needed in wide sample scale.

\section{COMPETING INTEREST}

There is no conflict of interest. There is no fund from any source.

\section{AUTHOR'S CONTRIBUTION}

All authors contributed to the conception and design of the survey. HR and SH analyzed the data and drafted the first version of the manuscript. NM and OA critically revised the manuscript. All authors read and approved the final manuscript.

\section{References}

[1]. Cordero L, Ayers LW, Miller RR, Seguin JH, Coley BD: Surveillance of ventilator-associated pneumonia in very-low-birth infants. Am J Infect Control. 2002; 30: 32-39.

[2]. Fogelia E, Dawn M, Elward A: Ventilator-associated pneumonia in neonatal and pediatric intensive care unit patients. Clin Micro Rev. 2007; 20:409-425.

[3]. Ibrahim EH, Mehringer L, Prentice D: Early versus late enteral feeding of mechanically ventilated patients: results of a clinical trial. JPEN J Parenter Enteral Nutr. 2002; 26: 174-181.

[4]. Tablan OC, Anderson LJ, Besser R: Guidelines for prevention of health-care-associated pneumonia, 2003: recommendations of $\mathrm{CDC}$ and the Healthcare Infection Control Practices Advisory Committee. Am J Crit Care. 2004; 53: 1-36.

[5]. Elward AM, Warren DK,Frases VJ: Ventilator-associated pneumonia in pediatric intensive care unit patients: risk factors and outcome. J Pediatr. 2002; 109: 758-764.

[6]. Curley MA, Schwalenstocker E, Deshpande JK, Ganser CC, Bertoch D, Brandon J, Kurtin P: Tailoring the institute for Health care improvement 100,000 lives Campaign to pediatric settings: the example of ventilator-associated pneumonia. Pediatr.Clin.N.Am. 2006; 53: 1231-1251.

[7]. Yildizdas D, Yapicioglu H, Yilmaz HL: Occurrence of ventilator-associated pneumonia in mechanically ventilated pediatric intensive care patients during stress ulcer prophylaxis with sucralfate, ranitidine and omeprazole. J Crit Care. 2002; 17: $240-245$.

[8]. Nolan T, Berwick DM: ALL or none measurement raises the bar on performance. JAMA. 2006; 295: 1168-1170.

[9]. Almuneef M, Memish ZA, Balkhy HH, Alalem H, Abutaleb A: Ventilator-associated pneumonia in a pediatric intensive care unit in Saudi Arabia: a 30 - month prospective surveillance. Infect Control Hosp Epidemiol. 2004; 25: 753-758.

[10]. Yuan TM, Chen LH, Yu HM: Risk factors and outcomes for ventilator-associated pneumonia in neonatal intensive care unit patients. J perinat Med. 2007; 35: 334-8

[11]. Torres A, Aznar R, Gatell JM: Incidence, risk, and prognosis factors of nosocomial pneumonia in mechanically ventilated patients. Am Rev Respir Dis. 2002; 142: 523-528.

[12]. Davis K, Evans SL, Campbell RS: Prolonged use of heat and moisture exchangers does not affect device efficiency or frequency rate of nosocomial pneumonia. Crit Care Med. 2000; 28:1412-1418.

[13]. Hina Gadani, Arun Vyas, Akhya Kumar: A study of ventilator-associated pneumonia: Incidence, outcome, risk factors and measures to be taken for prevention. Lung India. 2010; 54: 535-540.

[14]. Dorothy B, Zambuto A, O'Donnell C, Silva J: Adherance to ventilator- associated pneumonia bundle and incidence of ventilatorassociated pneumonia in Surgical Intensive Care Unit. Am J Surg. 2010; 145: 465-470. 